\title{
Relasi Gender Dalam Sistem Kekerabatan Matrilineal
}

\author{
Angelius Chrisantho Marician Sile*, I Wayan Suwena, Ni Luh Arjani \\ Prodi Antropologi, Fakultas Ilmu Budaya, Unud \\ [chrisantomarician@gmail.com] \\ Denpasar, Bali, Indonesia \\ *Corresponding Author
}

\begin{abstract}
Doka Nikisi'e is a village located in Ngada district which adheres to the matrilineal kinship system. However, even though women holding rights in traditional houses, men also have important roles in the kinship system in the village of Nikisi'e. Therefore, to avoid discrepancy and insurgency, it's necessary to have a good gender relation in both case. For Doka Nikisi'e people, even though the matrilineal kinship system greatly glorifies women, they still consider that this's not to give women an absolute power, but solely for the sake of harmony between both side. The matrilineal kinship system in DokaNikisi'e can be studied by applying Ratna Megawangi's nurture and nature theory, called role theory. Robert Linton. While the concepts used as a reference in this study are concept of gender, kinship system concept and matrilineal concept. This research is a qualitative research which is obtained by ethnographic research models. Data collection techniques used in this research are observation, interviews, literature studies, and data analysis that is useful for processing objects in the research location. The results of this research shows that there is a process in the matrilineal kinship system in Doka Nikisi'e village which explains the stages of the matrilineal kinship is formed through the marriage system. And in this process explained the classification of roles between men and women and allotment of inheritance in traditional houses.Besides explaining the process, this research also explains the significations contained in the matrilineal kinship system in DokaNikisi'e village.
\end{abstract}

Key words: gender relations, kinship system, matrilineal

\begin{abstract}
Abstrak
Kampung Doka Nikisie merupakan salah satu kampung di kabupaten Ngada, yang menganut sistem kekerabatan matrilineal,dimana garis keturunan di kampung ini, mengikuti garis keturunan ibu. Akan tetapi walaupun perempuan yang memegang hak dalam rumah adat, laki-laki juga mempunyai peran yang penting dalam sistem kekerabatan di kampung Doka Nikisi'e. Oleh karena itu, agar tidak terjadi perbedaan dan kekacauan, diperlukan sebuah relasi gender yang baik antara keduanya. Dalam penelitian ini adapun permasalahan yang kaji oleh penulis yaitu, bagaimanakah proses dan makna relasi gender di Kampung Doka Nikisie. Sistem kekerabatan matrilineal di kampung Doka Nikisi'e dikaji dengan mengaplikasikan teori nurture dan nature Ratna Megawangi,serta teori peran dari Robert Linton. Sedangkan konsep yang digunakan sebagai acuan dalam penelitian ini, yaitu konsep Relasi, konsep Gender, konsep sistem kekerabatan, dan konsep matrilineal. Penelitian yang dilakukan adalah penelitiian kualitatif dan diperoleh dengan model penelitian etnografi, teknik pengumpulan data yang digunakan adalah observasi, wawancara, studi pustaka, serta analisis data, yang berguna untuk mengolah
\end{abstract}


temuan di lapangan. Hasil penelitian memperlihatkan bahwa terdapat sebuah proses dalam sistem kekeraban matrilineal dikampung Doka Nikisi,e, yang didalamnya menjelaskan mengenai tahapan-tahapan terbentuknya sebuah sistem kekerbatan matrilineal yang terjadi melalui sistem perkawinan, didalam proses ini dijelaskan mengenai pembagian peran antara keduanya serta pembagian harta warisan dalam rumah adat. Selain menjelaskan mengenai proses, hasil penelitian juga menjelaskan mengenai makna-makna yang ada didalam sistem kekerabatan matrilineal di kampung Doka Nikisi'e. Makna tersebut memiliki nilai-nilai yang berguna bagi masyarakat Doka, terutama bagi generasi-generasi berikutnya.

\section{Kata kunci: Relasi gender, Sistem kekerabatan, matrilineal}

\section{PENDAHULUAN}

Nusa Tenggara Timur merupakan salah satu provinsi di indonesia yang terletak dibagian Tenggara Indonesia. Provinsi Nusa Tenggara Timur memiliki beraneka ragam suku dan budaya. Setiap suku mempunyai adat dan kebudayaan yang berbeda beda, Dengan adanya perbedaan itu menjadikan Nusa Tenggara Timur menjadi kaya akan kebudayaan, baik dalam bahasa, kesenian, religi, sistem pengetahuan, mata pencaharian dan sistem kekerabatan (sistem perkawinan). Di kabupaten Ngada memiliki sistem kekerabatan adat yang begitu kental. Ada tiga jenis sistem kekerabatan di kabupaten Ngada yaitu " Di'i Dhano" (bentuk perkawinan yang mengikuti garis keturunan ibu), dalam sistem kekerabatan ini, anak menghubungkan dirinya dengan kerabat ibu berdasarkan keturunan perempuan secara unilateral (Fitratmoko 2017 : 3-4) " Pasa " atau belis dan sistem perkawinan menurut darah sejati . Dalam tradisi adat Ngada setiap laki-laki dan perempuan yang sudah beranjak dewasa (So'o Hoga Bu'e Hoga) yang sudah siap berumah tangga, orang tua membebaskan anaknya dalam memilih jodoh, tetapi harus sederajat statusnya, karena ada daerah-daerah di Kabupaten Ngada yang masih menganut sistem stratifikasi sosial yaitu rang atas $\left(G a^{\prime} e\right)$ rang tengah ( $G a^{\prime} e$ Kisa) rang bawah ( $\mathrm{Ho}^{\prime} \mathrm{o}$ ).

Sebagai salah satu kampung yang menganut sistem kekerabatan matrilineal
Kampung Doka Nikisi'e masih melaksanakan tradisi ini sesuai dengan warisan leluhur, dimana hal ini kita bisa lihat pada setiap $S a^{\prime} o$ (rumah adat) di kampung Doka Nikisi'e terdiri atas dua Sa'o yaitu Sa'o Saka Pu'u dan Sa'o Saka Lobo'. Sa'o Saka Pu'u dipandang sebagai asal utama sebuah suku, dimana Sa'o Saka Pu'u ini juga merupakan rumah dari perempuan tertua dalam suku, yang biasa ditandai dengan miniatur bhaga ( semacam rumah-rumahan kecil sebagai simbol leluhur perempuan). $P u^{\prime} u$ sendiri berarti pokok, atau sumber yang dalam konteks ini merujuk pada sumber kehidupan yakni dari tubuh perempuan. Sedangkan Sa'o Saka Lobo ditandai dengan simbol leluhur lelaki berupa Ata atau ornamen patung kayu dengan memegang tombak dan parang.

Masyarakat Doka Nikisi,e, menganggap Ine (mama atau ibu) merupakan sosok yang sakral dan bernilai bagi mereka. Pembagian peran laki laki dan perempuan ini dipandang sebagai sesuatu yang adil, dimana peran perempuan dan laki laki harus saling melengkapi satu sama lain bukan saling menguasai satu sama lain, meskipun laki -laki berwenang untuk mengambil keputusan, namun keputusan dibuat dengan mendengarkan pertimbangan dari kaum perempuan.

Dalam Sistem kekerabatan matrilineal di Kampung Doka Nikisi'e, memang kaum wanita mempunyai hak dan peran yang sangat besar atau peran 
dan status wanita telah ditetapkan oleh budaya (Anggreni 2014: 57-58) akan tetapi, kaum laki- laki juga dapat menyamai peran kaum perempuan apabila kaum laki laki sudah mengikuti upacara $\mathrm{Be}^{\prime} \mathrm{o} S \mathrm{Sa}^{\prime} \mathrm{o}$. Upacara $\mathrm{Be}$ 'o $\mathrm{Sa}$ 'o merupakan salah satu rangkain dari upacara perkawinan yang harus diikuti kaum laki -laki dimana sebelum kaum laki laki memasuki $\mathrm{Sa}^{\prime}$ o (rumah) dia harus membawa seekor kerbau sebagai simbol bahwa dia sudah memenuhi persaratan sesuai dengan hukum adat yang ada dikampung tersebut. Apabila kaum laki- laki sudah memenuhi persaratan tersebut maka kedudukannya akan sama dengan kaum wanita serta semua saudara laki lakinya. Besar kecilnya Nominal Mahar dan banyaknya harta yang dibawa sangat bergantung kepada strata sosial keluarga pihak perempuan (Sa'dan 2016 : 135-136)

Namun seiring berjalannya waktu, pola relasi dalam sistem kekerabatan matrilinieal ini mulai mengalami pergeseran sebab, sekalipun struktur matrilineal serta simbolisme adat mengagungkan perempuan, namun kewenangan, kepemimpinan serta akses terhadap pengetahuan tentang adat, hukum, politik, teknologi, dikuasai oleh laki-laki. Dengan kata lain segala keputusan diambil alih oleh laki-laki, tidak lagi menunggu kesepakatan dari kaum perempuan, hal ini karena adanya faktor 'Nature' yang melekat pada lakilaki maupun perempuan, sehingga sering terlihat dimana kaum laki -laki duduk bersama dan membahas sebuah masalah sendirian sementara kaum perempuannya memasak dan menyajikan makanan. Oleh karena itu, dengan adanya perubahan peran yang terjadi, diharapakan dapat memberi suatu pengetahuan baru bagi masyarakat bahwa, sekalipun garis keturunan bersifat matrilineal, akan tetapi ada pekerjaan-pekerjaan, yang tidak mampu dikerjakan oleh perempuan sehingga laki-laki yang harus mengerjakan pekerjaan tersebut. Hal ini karena Perempuan dan laki-laki berbeda secara badaniah, hal tersebut menyebabkan perempuan dan laki-laki mempunyai fungsi yang berbeda dalam kehidupan (Ariani,2015:42-43)

Perubahan diatas tentunya, mempunyai makna tersendiri bagi masyarakat Doka Nikisi,e dimana, masyarakat dapat menyadari bahwa peran dalam suatu sistem kekerabatan dapat berubah, karena adanya faktor biologis, sehingga baik laki-laki dan perempuan harus bekerja sama dan saling melengkapi dalam menyikapi perubahan peran yang terjadi dalam suatu sistem kekerabatn, khususnya sistem kekerabatan matrilineal. Oleh karena itu, dengan adanya relasi gender yang terjadi pada masyarakat Kampung Doka Nikisi,e, Sesuai dengan uraian diatas, fenomena mengenai garis keturunan matrilineal merupakan permasalahan yang menarik untuk dikaji, oleh karena itu penulis dalam penelitian ini berminat mengkaji tentang: "Relasi Gender dalam Sistem Kekerabatan Matrilineal.

Berdasarkan latar belakang di atas, dapat dirumuskan permasalahan sebagai berikut: Bagaimanakah proses relasi gender yang terjadi dalam sistem kekerabatan matrilineal di kampung Doka Nikisi'e?, Apa makna relasi gender yang terjadi dalam sistem kekerabatan matrilineal di Kampung Doka Nikisi'e?

Adapun tujuan dari penelitian ini, sebagai berikut.1) Tujuan umum dari penelitian ini ialah untuk mengetahui relasi gender dalam sistem kekerabatan matrilineal dan apa sajakah makna dari sistem kekerabatan tersebut 2) Mengetahui dan mengungkapkan secara khusus relasi gender dalam sistem kekerabatan matrilineal dikampung Doka Nikisi'e 


\section{METODE}

Penelitian Ini menggunakan jenis penelitian kualitatif yaitu jenis penelitian yang bertujuan untuk menggambarkan bagaimana relasi gender yang terjadi dalam sistem kekerabatan matrilineal di kampung Doka Nikisi'e. Penelitan ini menggunakan metode penelitian etnografi. Sedangkan Sumber data yang digunakan adalah sumber data primer dan sumber data sekunder. Sumber data primer diperoleh melalui hasil observasi dan wawancara kepada informan. Sedangkan sumber data sekunder yaitu data yang diperoleh melalui dokumen desa yang menjelaskan tentang gambaran umun di Kampung Doka Nikisi'e seperti, Laporan Pertanggung jawaban Desa, peta Desa dan Gambar struktur organisasi Desa. Peneliti menggunakan instrumen penelitian berupa kamera, perekam dan handphone.

Teknik pengumpulan data adalah cara yang dilakukan oleh peneliti untuk mengumpulkan data. Adapun beberapa teknik yang diakukan oleh peneliti saat melakukan penelitian yaitu,1) Teknik penentuan informan; 2) Obeservasi partisipan; 3) wawancara; 4) studi kepustakaan. Peneliti menggunaan tahapan analisis data dari Miles dan Huberman yaitu, membangun sajian, memasukan data, menganalisis data. Analisis penelitian kualitatif menurut Miles dan Hubermas dapat memberikan peneliti kesimpulan yang mampu menjawab permasalahan penelitian kualitatif.

\section{HASIL DAN PEMBAHASAN}

\section{Proses relasi Gender dalam sistem kekerabatan matrilineal}

Masyarakat Doka Nikisi'e merupakan salah satu penganut sistem kekerabatan matrilineal di provinsi Nusa Tenggara Timur dimana, sistem kekerabatan tersebut terbentuk melalui simbol Ngadhu dan Bhaga. Ngadhu dan Bhaga merupakan lambang eksistensi masyarakat Doka Nikisi,e dimana dari Ngadhu dan Bhagalah masyarakat Doka Nikisi'e dapat mengetahui dari mana sukunya berasal, dari mana keluarganya, dan dari mana nenek moyangnya ,sehingga semuanya diperhitungan dalam sudut pandang kehidupan masyarakat Doka Nikisie, bahwa sistem kekerabatan merupakan bagian yang sangat penting dalam struktur sosial.( Hermaliza 2011: 123-124). Oleh karena itu, dalam pembentukan sebuah sistem kekerabatan matrilineal, terdapat berbagai tahapan dan proses didalamnya antara lain:

Pertama Beti tei tewe da moni neni. tahapan ini merupakan tahapan awal yang biasa dialami oleh setiap pasangan yang berkaitan melalui proses jatuh cinta. Pada jaman dahulu proses beti tei ini biasanya terjadi pada event-event tradisional. Apabila sudah mulai dibicarakan mengenai perkawinan, maka seorang pemuda akan diingatkan untuk mulai mencari seorang gadis dari lingkungan keluarga, atau dalam bahasa daerahnya adalah " Netu Tuka Ghi" (tingkat sosial yang sama), Hal ini tentu akan menjadi pertimbangan bagi si pemuda, terkadang ia memang keberatan, sehingga mau tidak mau dia harus bisa mendapatkan jodoh di luar lingkup keluarga atau bisa juga di luar kampung Doka Nikisi,e. oleh karena itu ia harus menyesuaikan diri agar bisa melaksanakan tugas tersebut.

Kedua Beku Mebhu Tana Tigi. Tahapan bertujuan untuk melakukan pendekatan dengan gadis idaman dan keluarga dari calon yang bersangkutan. Pada tahap ini laki-laki mengadaptasi diri dengan gadis dan keluarga. Seorang gadis tidak akan pernah meminang sendiri dan juga tidak akan menyuruh kedua orang tuanya meminang, walaupun mereka memang sangat menyukai 
seorang pemuda untuk dijadikan sebagai menantu.

Ketiga Naa Boro. Pada tahap ini biasanya, setelah merasa cocok maka laki-laki yang bersangkutan akan mendiskusikan dengan pihak keluarga tentang kecocokan untuk menjalin hubungan perkawinan dan membicarakan persyaratan yang harus dipenuhi jika anak mereka serius untuk meminang gadis idamannya. Dalam pembicaraan tersebut biasanya dari pihak laki-laki akan menyiapkan hadiah tabung kapur sirih.

Keempat Tege Tua Manu Tahapan ini dilaksanakan Setelah upacara naa boro, maka akan dilanjutkan dengan tege tua manu( membawa ayam dan moke/tuak putih) ke rumah calon istri hal ini merupakan simbol keiklasan dan ketulusan hati kedua mempelai. Upacara ini dipandang sakral karena upacara ini merupakan salah satu upacara yang wajib dilaksanakan oleh semua pasangan yang akan meminang maupun dipinang. Pada tahapan ini laki-laki bersama rombongan dan keluarga beriringan menuju rumah calon istri atau ke dalam sao meze, lalu mereka akan meminta dan memohon doa kepada ine ebu( nenek moyang) agar semua rangkaian acara yang akan dilaksanakan kedepannya bisa berjalan lancar sesuai yang diharapakan.

Kelima belis. Diseluruh wilayah Ngada khususya dikampung Doka nikisi'e apapun yang berkaitan dengan perkawinan adat harus dilakukan dengan cara belis. Belis dapat dikatakan juga sebagai mahar karena sebagai tanda kesungguhan seorang laki-laki untuk menikahi seorang wanita ( Wibisana 2016: 188-189) Belis terdiri dari banyak bagian, yang masing-masingya mempunyai nama tersendiri, yang didalamnya membahas mengenai satu jumlah uang atau nilai tertentu. Akan tetapi, baik nama, jumlah maupun yang terungkap didalamnnya mempunyai aturan yang berbeda- beda didalamnya. untuk masyarakat doka nikis,e biasanya yang mendapatkan belis adalah ayah, ibu, saudara-saudara, saudari ibu, orang tua angkat. Yang mendapat bagian paling besar adalah saudara laki-laki ibu. Apabila belis ibu belum dibayar maka ia mendapat seluruh belis anak gadis yang ingin dikawinkan tersebut. Apabila ada sauadara atau saudari ibu yang meninggal maka keluarganya yang terdekat bisa menggantikannya. Belis dapat dikatakan juga sebagai alat penukar antara pemberi dan penerima perempuan ( Kleden 2017 : 65-66 ).

Keenam Seza Setelah Tege Tua Manu dan penyerahan belis maka akan dilanjutkan dengan zeza yang merupakan tahapan puncak dalam mengesahkan pasangan wanita dan laki-laki untuk hidup berdampingan suami istri secara adat, dan mulai melakukan pembagian peran atau relasi gender (Puspitawati, 2010:2-3) Pada kesempatan ini kedua mempelai, secara adat sudah resmi dan sah menjadi suami istri. Akan tetapi, mereka belum diperbolehkan tidur bersama dan melakukan hubungan layaknya suami dan istri.

\section{Makna sistem kekerabatan Matrilineal}

Makna Simbolis. Menurut bapak Hermanus Watu Masyarakat Doka Nikisi,e percaya bahwa didalam bhaga terdapat ungkapan adat yang sakral yaitu: " ana sawa baa lau lewa, sawa da baa too ngii go logo too milo malo, yang berarti bhaga merupakan tempat perlindungan bagi wanita(anafai) yang mempunyai teladan yang baik dan kehadirannya akan sangat menyucikan masa ata (semua orang)." (wawancara 31 desember 2018)

Ungkapan tersebut menjelaskan bahwa dalam sistem kekerabatan di kampung Doka Nikisi'e, bhaga merupakan sebuah miniatur yang merupakan tempat seorang 
wanita berlindung, berdoa dan memohon kepadanya. Dari bhaga juga para wanita dapat mengikuti teladannya karena kehadiranya didunia ini dapat menyucikan semua orang, khususnya masyarakat Doka Nikisi'e. Filosofi ini menjadi ungkapan untuk mengagumi dan meluhurkan kasih keibuan dan kesucian pokok dari seeorang wanita yang patut untuk diteladani, sehingga ia akan mempunyai keturunan yang sehat dan ia akan semangat dalam melayani didalam rumah tangganya, termasuk pembagian kerja secara Gender ( Probosiwi 2015 : 49-50). Hal ini terdapat pada miniatur bhaga yang merupakan simbolisasi rahim perempuan. Bhaga merupakan representasi kehadiran leluhur wanita, yang didalamnya terdapat nilai kesucian yang menjadi asas dan dasar hidup perkawinan. Oleh karena itu kehidupan manusia tidak terlepas dari penggunaan simbol-simbol ( Hutapea, 2016 : 1-2)

Makna sejarah. Makna sejarah yang terkandung didalam relasi gender dalam sistem perkawinan matrilineal adalah sebagaimana dijelaskan terdahulu bahwa perkawinan matrilineal merupakan warisan leluhur. Perkawinan menjelaskan tentang sejarah kehidupan masyarakat Ngada khususnya di daerah Doka dimana sejak awal nenek moyang mereka lahir sampai dengan hari ini, hal itu merupakan suatu sejarah panjang yang hingga saat ini masih di pegang teguh oleh masyarakat Doka Nikisi,e. Berdasarkan sejarah pulalah semua masyarakat kampung Doka nikisi,e dapat mengetahui bahwa nenek moyang mereka awalnya berasal dari campur tangan bangsa india.

Sejarah mempunyai makna yang begitu sakral bagi masyarakat Doka Nikisi,e dimana, jika generasi penerus saat ini melupakan sejarah maka segala nilai- nilai yang terkandung dalam budaya perkawinan akan pudar atau hilang. Oleh karena itu diperlukan keseriusan dalam mengerti dan memaahami sejarah, agar apa yang sudah diperjuangkan oleh nenek moyang, tidak hilang dan tetap terjaga dari generasi yang lalu ke generasi berikutnya.

Makna Religius. Dalam kehidupan masyarakat Doka Nikisi,e, percaya bahwa ada kekuasaan dan kekuatan tertinggi yaitu " Dewa Zeta" atau kekuatan baik serta " Nitu Zale" atau kekuatan jahat. Masyarakat doka nikisi,e mempunyai persepsi bahwa dunia merupakan " Ota Ola" dimana ota ola merupakan tempat manusia hidup bersama atau yang dilukiskan dalam bahasa adat: lobo papa tozo, tara papa dhaga( saling ketergantungan satu sama lain). Sehingga manusia diciptakan untuk saling melengkapi dan saling mencintai satu sama lain.

Berdasarkan hasil wawancara peneliti dengan bapak hendrikus ngaji beliau menjelaskan tentang apa itu konsep dewa zeta nitu zale, berikut pemaparannya

"Dewa zeta nitu zale, terdiri dari empat kata yang mempunyai artinya tersendiri. Masyarakat doka nikisi,ee memahami dewa adalah sebagai satu dasar atau satu sumber yang modhe dan tersembunyi. Wujud tertinggi yang diagungkan oleh masyarakat doka nikisi,e adalah Ema dewa. Ema adalah Tuhan atau bapak yang selalu memberikan sesuatu, yang penuh kasih sayang dan yang selalu menjadi sandaran manusia di dalam hidupnya. Dewa adalah wujud tertinggi sebagai penguasa manusia dan alam semesta Allah disebut dengan berbagai nama yaitu Dewa Zeta,Tua Dewa,Mori Dewa, dan Ema Mori Bhu. ( wawancara 2 january 2019)

Dalam uraian diatas dijelaskan bahwa masyarakat Doka Nikisi'e mempunyai sistem dan konsep religi yang begitu kuat. Sama halnya dengan masyarkat lainnya yang ada di Indonesia 
terdapat kepercayaan religius yang ada dikampung Doka Nikisi'e yang tak dapat dipisahkan oleh ruang dan waktu. Oleh karena itu Dewa zeta dipahami sebagai Tuhan yang menjadi penguasa langit dan keberadaannya adalah sebuah misteri yang tidak kelihatan dan diyakini akan mendatangkan kebaikan jika manusia berbuat baik, dan akan mendatangkan malapetaka jika manusia tidak setia kepadaNya. Sehingga masyarakat Doka Nikisi,e selalu percaya bahwa segala sesuatu yang diberikan akan kembali kepadaNya.

Makna Persatuan dan Kesatuan. Menurut bapak Darius Bomo( kepala desa),di dalam sistem kekerabatan matrilineal di kampung Doka Nikisi'e terdapat beberapa fungsi persatuan dan kesatuan yaitu:

" menurut saya relasi yang terjadi bukan hanya antara kedua pasanganyang akan menikah akan tetapi, moment ini juga bisa dijadikan sebagai tempat untuk berkumpul, dan bersatu dalam keluarga besar. Bahkan mungkin jika ada beberapa anggota keluarga yang berpisah karena merantau, kuliah dan sebagainya, maka dengan adanya upacara perkawinan yang terjadi di kampung doka nikise ini, maka semua masyarakat setempat kembali bersatu. Disana pasti ada kegembiraan, kedamaian dan suasana yang demikian, maka segala yang direncanakan, dilakukan akan berhasil dengan cepat dan baik adanya.(wawancara 3 Januari 2019)

Uraian diatas menjelaskan bahwa persatuan dan kesatuan merupakan salah satu aspek penting yang selalu di pegang teguh oleh masyarakat Doka Nikisi'e, hal ini karena mereka meyakini bahwa sebagai makhluk sosial mereka tidak mungkin melakukan segala macam pekerjaanya sendiri, mereka juga butuh bantuan orang lain yang bertujuan untuk menyatukan dan saling menguatkan satu sama lain. Apalagi hal-hal yang menyangkut perkawinan tentu dibutuhkan kerja sama dari seluruh masyarakat Doka Nikisi'e untuk saling menghargai satu sama lain. Makna Musyawarah Dan Mufakat. musyawarah yang terjadi dikampung Doka nikisi'e biasanya disebut soro mazi. Soro mazi merupakan musyawarah adat yang dilakukan oleh seluruh keluarga besar sebuah klan atau suku yang bertempat di sa'o meze (rumah adat) dalam musyawarah ini biasanya keputusan keputusan yang diberikan harus bersifat adil da rasional hal ini dilakukan agar tidak terjadi pertengkaran antara kaum muda dan kaum tua serta kaum laki-laki dan kaum perempuan. Dalam sistem kekerabatan matrilineal di kampung Doka Nikisi'e walaupun yang memipin rapat adalah seorang laki-laki, akan tetapi peran seorang perempuan sangat penting dalam musyawarah ini. Dimana segala keputusan harus menunggu persetujuan dari pihak perempuan, jika tidak musyawarah akan di hentikan

Makna sosial. Sistem kekerabatan matrilineal telah memberi pedoman dalam pergaulan hidup antara seorang laki-laki dan seorang perempuan, yang berarti kaum laki-laki sebagai makhluk yang kuat harus melindungi perempuan sebagai makhluk yang lemah lembut. kesenjangan Relasi dalam sistem perkawinan matrilineal ini juga merupakan hasil budaya masyarakat yang mengatur segala kehidupan masyarakat di masa sekarang, dan dimasa yang akan detang, sehingga dengan hal ini, maka akan terciptanya suatu relasi yang baik didalam rumah tangga(suami dan istri) maupun dalam kelompok masyarakat. Kualitas pernikahan merupakan suatu derajat pernikahan yang dapat memberi kebahagiaan dan kesejahteraan bagi suami dan istri ( Tyas $2017: 7-8$ )

Makna Moral. Dalam kaitannya dengan moral, didalam sistem 
perkawinan matrilineal diajarkan bahwa terdapat keteraturan sikap dan tingkah laku manusia dalam hubungannya dengan keseluruhan hidup dan martabat manusia. Moral juga merupakan salah satu nilai atau kaidah yang terkandung dalam suatu relasi yang terjadi dalam sisitem perkawinan matrilineal di kampung ini, dimana baik laki-laki maupun perempuan, dalam berelasi diajarkan tingkah laku yang baik dan sopan serta berusaha menjaga diri agar tidak menyimpang dari norma adat yang berlaku. Kedua pasangan harus tetap harmonis baik secara adat maupun secara gereja.

Sesuai dengan norma dan aturan yang ada dalam sistem kekerabatan matrilineal di Kampung Doka nikisi,e ini, maka manusia dituntut untk hidup sesuai dengan ajaran budaya itu sendiri yaitu, tingkah laku yang baik, yang sopan, santun dalam pergaulan terutama dengan lawan jenis, karena semuanya akan menentukan kehidupan yang lebih baik di kemudian hari. Manusia dituntut untuk mencapai keutuhan, dalam seluruh kehidupan, yang bermanfaat bagi pribadi manusia itu sendiri, dimana ia akan dicintai, di sayangi, dihormati dan bahkan disegani oleh orang lain dalam kehidupan bersama. Segala macam sikab yang meletakan laki-laki dan perempuan secara tidak sejajar harus dilenyapkan, karena secara moral tidak akan menciptakan keproduktifan

Muthmainnah 2006 : 210-211)

\section{SIMPULAN}

Berdasarkan pembahasan dan analisis data mengenai relasi gender dalam sistem perkawinan matrilineal di kampung doka nikisi'e, kecamatan jerebu'u, kabupaten ngada dapat disimpulkan sebagai berikut :Masyarakat Doka Nikisi,e merupakan salah satu daerah di kabupaten ngada yang hingga saat ini masih menganut sistem kekerabatan matrilineal,dimana hal ini dapat dilihat dari proses dan tahapan kegiatan pernikahan adat masyarakat Doka Nikisi'e. keturunan perempuan mempunyai hak untuk mewarisi tanah,rumah,massing-masing woe (suku). Setelah menikah, seorang lelaki akan menjadi bagian dari keluarga istrinya, demikian pula anak-anak hasil dari pernikahan kedua pasangan akan tinggal di rumah istrinya

Masyarakat Doka nikisie baik lakilaki maupun perempuan, menyadari bahwa sistem kekerabatan matrilineal terebut mempunyai beberapa makna tersendiri dimana, makna tersebut dapat dilihat bahwa setiap masyarakat Doka Nikisi'e memiliki rumah adat yang didalamnya terdapat ngadhu dan bhaga, dimana ngadhu merupakan representasi dari laki-laki, sedangkan bhaga merupakan representaasi dari kaum perempuan.

Setelah melakukan penelitian, menganalisis dan menyajikan kembali proses dan makna yang terjadi dalam sistem kekerabatan matrililineal, maka penulis menyampaikan beberapa saran:

Pertama, bagi masyarakat Doka Niksi,e. penulis berharap agar tetap mempertahankan adat perkawinan, khususnya perkawinan matrilineal, Sebagai kebudayaan daerah yang perlu dijaga, dilestarikan dan dipertahankan. Kedua, bagi kaum muda, diharapkan bersikap terbuka dan membangun, serta dapat menyiapkan diri secara baik apabila hendak memasuki jenjang perkawinan demi memebentuk keluarga yang harmonis ditengah-tengah hidup bermasyarakat. Ketiga, kepada program studi Antropologi. Hendaknya mendidik, mendorong dan membina mahasiswa untuk mencintai dan menghayati nilainilai luhur budaya, demi menghasilkan tamatan yang berwawasan budaya. Keempat kepada lembaga pemerintahan. Hendaknya ada perhatian dari pemerintah 
kepada masyarakat atau memberikan faktor pendukung seperti mendirikan sanggar-sanggar budaya sebagai sarana pengembangan khususnya dibidang kebudayaan.

\section{REFERENSI}

Ariani, Iva. 2015 " Nilai Filosofis Budaya Matrilineal Di Minangkabau" Yogyakarta: Jurnal Filsafat. Vol. 25 No 1 : 42-43

Arndt, Paul, SVD. 2009. Masyarakat Ngada (Keluarga, Tatanan Sosial,Pekerjaan dan Hukum Adat). Flores: Nusa Indah

Fakih Mansour, 2008, Analisis Gender Dan Transformasi Sosial, Yogyakarta

Fitriatmoko, Riyan. 2017 “ Praktik Perkawinan Campuran Antar Masyarakat Adat Di Kota Batam Dan Akibat Hukumnya" Semarang : Jurnal S1 UNDIP. Vol 6 No 2 : 34

Hermaliza, Essi. 2011 " Sistem Kekerabatan Suku Bangsa Kluet" Banda Aceh: Jurnal Widyariset Vol 14 No 1: 123-124

Hutapea, Edison 2016 “ Identifikasi Diri Melalui Simbol-Simbol Komunikasi” Jakarta: Jurnal Bricolage Vol 2 No 1 : 1-2

Kleden, Dony. 2017 "Belis Dan Harga Seorang Perempuan Sumba" Sumba Barat Daya: Jurnal Studi Budaya Nusantara. Vol 1 No 1 : 65-66

Likha, Sari, Anggreni. 2014 “ Aktivitas Wanita Di sector Publik Dalam Pemberitaan Surat Kabar"
Surakarta : Jurnal Ilmu Komunikasi Vol 2 No 1: 57-58

Megawangi, Ratna. Membiarkan Berbeda(edisi revisi). Indonesia Heritage Foundation : Depok

Muthmainnah, Lailiy 2006 “ Membincang Kesetaraan Gender Dalam Islam " Yogyakarta : Jurnal Filsafat Vol 40 No 2: 210-211

Puspitawati, Herien. 2010 “ Persepsi Peran Gender " Purwokerto: Jurnal Studi Gender Dan Anak Vol 5 No 1 : 2-3

Ratih, Probosiwi 2015 “Perempuan Dan Perannya Dalam Pembangunan Kesejahteraan Sosial" Yogyakarta: Jurnal Kajian Ilmu Admnistrasi Negara Vol. 3 No. 1: 49-50

Sa'dan, Masthuriyah 2016 “ Tradisi Perkawinan Matrilokal Madura" Yogyakarta : Jurnal Kebudayaan Islam. Vol 14 No 1 : 135-136

Tyas, Fatma 2017 “ Kualitas Pernikahan Dan Kesejahteraan Keluarga Pada Pasangan Yang Menikah Muda" Bogor : Jurnal Ilmu Keluarga Dan Konsumen Vol 10 No 1 : 7-8

Wibisama, Wahyu. 2016 “ Pernikahan Dalam Islam "Bandung: Jurnal Pendidikan Agama Islam Vol 14 No 2 : 188-189 